\title{
IN VITRO AND IN VIVO INTRACELLULAR DELIVERY OF QUANTUM DOTS BY MAUROCALCINE
}

\author{
Narendra Ram ${ }^{1,2}$, Isabelle Texier $^{3}$, Karine Pernet-Galley ${ }^{2,4}$, Cathy Poillot ${ }^{1,2}$, Fabienne \\ Pirollet $^{1,2}$, Michel Ronjat ${ }^{1,2}$, Annie Andrieux ${ }^{2,4}$, Christophe Arnoult ${ }^{1,2}$, Michel De Waard ${ }^{1,2^{*}}$ \\ ${ }^{1}$ Université Joseph Fourier, Grenoble Institute of Neuroscience, Research group 3 « Calcium Channels, \\ Functions and Pathologies », Site Santé, BP 170, 38042 Grenoble Cedex 09, France. \\ ${ }^{2}$ Inserm U836, Grenoble Institute of Neuroscience, Grenoble, France. \\ ${ }^{3}$ CEA Grenoble/LETI-DTBS, 17 rue des Martyrs, 38054 Grenoble Cedex, France. \\ ${ }^{4}$ Unité Inserm 836, Grenoble Institute of Neuroscience, Research group 1 «Physiopathologie du \\ Cytosquelette », Site santé Tronche, bâtiment Edmond Safra, Grenoble, France.
}

Short title: Cell delivery of quantum dots by maurocalcine

Correspondence to: Dr. Michel De Waard

Inserm U836, Grenoble Institute of Neuroscience, Université Joseph Fourier, Site Santé de la Tronche, Chemin Fortuné Ferrini, BP170, 38042 Grenoble Cedex 09, France.

Tel.: (33) 456520563

Fax : (33) 456520637

E-mail: michel.dewaard@ujf-grenoble.fr

\begin{abstract}
Maurocalcine is a new member of the increasing family of cell penetrating peptides. We report for the first time that this peptide is able to deliver quantum dots inside a variety of cells, both in vitro and in vivo. In vivo, maurocalcine produces intracellular delivery of the nanoparticles without affecting the relative distribution of quantum dots within organs. The data stress out that maurocalcine can be used for intracellular delivery of functionalized nanoparticles in vivo.
\end{abstract}




\section{Abbreviations}

CdSe, cadmium-selenium; CdTe, cadmium-telluride; CHO, chinese hamster ovary; CPP, cell penetrating peptide; DRG, dorsal root ganglia; FACS, fluorescence activated cell sorting; $\mathrm{MCa}$, maurocalcine; $\mathrm{MCa}_{\mathrm{b}}$, biotinylated maurocalcine; $\mathrm{NGF}$, nerve growth factor; PBS, phosphate-buffered saline; Qdot, quantum dot; Strep, streptavidin.

\section{Introduction}

Semiconductor quantum dots, herein referred as Qdots, are new classes of fluorescent probes with a large surface to volume ratio, a property that is largely exploited to graft new functional entities at their surface. They possess excellent photo stability, that far exceeds that of conventional organic fluorophores, and high emission quantum yield, which leads to increased fluorescence detection sensitivity. Qdots consist of a core of semi-conducting material, typically cadmium-telluride (CdTe) or cadmium-selenium (CdSe) for emission in the visible to the near infrared domain, for which tissue auto-fluorescence and absorption are reduced. This core is most of the time covered by a shell composed of zinc sulfide $(\mathrm{ZnS})$, in order to improve the chemical stability and emission quantum yield of Qdot [15, 18]. These nanocrystals, produced in organic solvents, are further surface-modified for their stabilization in aqueous media and biological functionalization. In particular, the coating of the nanoparticles by a polyethylene glycol polymer (PEGylation) has been shown to improve their colloidal stability [13] and their blood circulation time [2] by reducing non specific opsonin binding. In this study, commercial streptavidin- $\mathrm{PEG}_{2000}$-Qdots (Invitrogen) are used.

These properties enlarge their usefulness in various biological applications. They have namely been used for immunostaining of membrane proteins [25] and staining of organelles like mitochondria or nuclei [11] in fixed cells, and for tracking single molecules in living cells by videomicroscopy [17, $14,6]$. In vivo imaging $[18,1,8,5,10]$ applications have also been reported. Qdot coated with watercompatible organic materials have been developed for multiphoton fluorescence imaging in vivo [12]. Peptides have been used to improve Qdot solubility in aqueous solution and kept bioactive for targeting cell surface proteins of interest [20]. In spite of this wealth of applications, the uses of Qdot for intracellular applications in vitro or in vivo are still limited because of their inability to cross the plasma membrane. Several experimental strategies have been developed to physically deliver the Qdots, including direct microinjection, but this limits the number of cells that can be studied, or electroporation [4, 26, 7]. Cell delivery of Qdots using lipofectamine, as for transfection of plasmids, results in the formation of Qdot aggregates [26]. None of these delivery systems seem promising for in 
vivo applications because of their limited cell penetration efficiencies. Recently, a different strategy of Qdot delivery has been developed that uses cell penetrating peptides (CPP). Polyarginine [24] and TAT [23] have been used for the delivery of Qdot into living cells in vitro or across the blood brain barrier in vivo, respectively. This delivery system sounds very promising because CPP have found many applications for the cell delivery of a wealth of cargoes including peptides, proteins, siRNA, peptide nucleic acids, cDNA or drugs [27]. Here, we report on the use of a new CPP, maurocalcine (MCa), to deliver Qdots both in vitro and in vivo. Originally used for its pharmacological properties as a peptide/toxin active on an intracellular channel, MCa was shown to possess the ability to efficiently carry various cargo molecules inside cells $[3,16,21,22]$. MCa is a 33 amino acid residue peptide isolated from the venom of the scorpion toxin Scorpio maurus palmatus that, as determined by ${ }^{1} \mathrm{H}$ NMR, possesses three disulphide bridges and is folded along an inhibitor cystine knot motif [19]. Folding occurs in such a manner that most of its basic residues are oriented towards one face of the molecule. The opposite face of the peptide is hydrophobic indicating the existence of a strong dipole moment capable to orient the molecule in an electrical field. The basic nature of the peptide is a feature shared by most cell penetrating peptides. MCa interacts with various negatively charged components of the cell surface, including lipids [16] and glycosaminoglycans [21]. This priming step is mandatory before the entry process itself of the peptide can occur. Initial studies have indicated the importance of macropinocytosis in the entry of MCa, at least when coupled to streptavidin (Strep) [21].

By using Fluorescence Activated Cell Sorting (FACS) and confocal microscopy, we show in the present study that Strep-Qdot, bound to biotinylated $\mathrm{MCa}\left(\mathrm{MCa}_{\mathrm{b}}\right)$, can efficiently be delivered in living $\mathrm{CHO}$ cells as well as primary neuronal cultures. The Qdots were found to be localized in endosomes in co-localization studies by confocal microscopy and on ultrastructural images by transmission electron microscopy. Inhibition of cell entry by amiloride suggests that macropinocytosis is implicated in the entry pathway of Strep-Qdot. Studying the in vivo distribution of the complex in mice indicates that the coupling of $\mathrm{MCa}_{\mathrm{b}}$ to Strep-Qdot does not alter Qdot organ distribution but allows cell penetration. These data indicate that, in this chemical configuration, $\mathrm{MCa}$ is a potent vector for the in vivo intracellular delivery of Qdots. These findings will undoubtedly enlarge the potential biological applications of $\mathrm{MCa}$ and Qdot for in vivo delivery of therapeutics.

\section{Materials and methods}

\subsection{Reagents}


Streptavidin-quantum dots excited at $585 \mathrm{~nm}, 655 \mathrm{~nm}$ or $705 \mathrm{~nm}$ (Strep-Qdot585, Strep-Qdot655 or Strep-Qdot705) were purchased from Molecular probes (USA) and streptavidin-gold particles (Strepgold, $15 \mathrm{~nm}$ diameter) from Aurion (Netherlands). On average, each Qdot and each gold particle contains 9 and 20 Strep molecules at its surface, respectively. Biotinylated maurocalcine $\left(\mathrm{MCa}_{\mathrm{b}}\right)$ was stock from a previous synthesis [16].

\subsection{Cell culture}

Chinese hamster ovary $(\mathrm{CHO})$ cell line (ATCC) was maintained at $37^{\circ} \mathrm{C}$ in $5 \% \mathrm{CO}_{2}$ in $\mathrm{F}-12 \mathrm{~K}$ nutrient medium (InVitrogen) supplemented with $10 \%(\mathrm{v} / \mathrm{v})$ heat-inactivated fetal bovine serum (InVitrogen) and 10,000 units/ml streptomycine and penicillin (InVitrogen).

\subsection{Primary culture of dorsal root ganglia (DRG)}

DRGs were isolated from 17 days old embryos of rat and initially treated with collagenase A at room temperature for $15 \mathrm{~min}$. Cells were later digested with $0.25 \%$ trypsin-EDTA for $10 \mathrm{~min}$ at $37^{\circ} \mathrm{C}$, followed by mechanical dissociation. Dissociated cells were platted on poly-L-lysine-coated (10 $\mu \mathrm{g} / \mathrm{ml})$ plates and grown in DMEM supplemented with $10 \%$ fetal bovine serum, $5 \mathrm{mg} / \mathrm{ml}$ glucose, $40 \mathrm{ng} / \mathrm{ml}$ gentamicin, $200 \mathrm{ng} / \mathrm{ml}$ nerve growth factor (NGF), and $10 \mu \mathrm{M}$ arabinoside $\mathrm{C}$ before assayed for cell penetration of the complex.

\subsection{Formation of $M C a_{b}$-streptavidin-quantum dots $\left(M C a_{b} /\right.$ Strep-Qdot) or $M C a_{b} /$ streptavidin-gold} complex $\left(M C a_{b} /\right.$ Strep-gold)

Soluble Strep-Qdot or Strep-gold were mixed with four molar equivalents of $\mathrm{MCa}_{\mathrm{b}}\left(4 \mathrm{MCa}_{\mathrm{b}} / 1\right.$ Qdot) for $2 \mathrm{hrs}$ at $37^{\circ} \mathrm{C}$ in the dark in PBS (phosphate-buffered saline) (in $\mathrm{mM}$ ): $\mathrm{NaCl} 136, \mathrm{Na}_{2} \mathrm{HPO}_{4} 4.3$, $\mathrm{KH}_{2} \mathrm{PO}_{4}$ 1.47, $\mathrm{KCl}$ 2.6, $\mathrm{CaCl}_{2} 1, \mathrm{MgCl}_{2}$ 0.5, $\mathrm{pH}$ 7.2. The fluorescence emission properties (wavelength and intensity) were not altered by the coupling of $\mathrm{MCa}_{\mathrm{b}}$ to Strep-Qdots (data not shown).

\subsection{Injection of Qdots into mice, organ isolation and blood collection}

For flow cytometry experiments, whole animal and organ imaging experiments, and tissue section imaging, $200 \mu \mathrm{L}$ of Qdots (65 pmol, $325 \mathrm{nM}$ in PBS 1X buffer) are injected intravenous via a catheter placed into the jugular vein of anesthetized OF1 mice (isofluorane/oxygen 3.5\%, and 1.5\% thereafter only for whole animal imaging). Three conditions were studied: control animals (non-injected), animals injected with Strep-Qdot705 alone, and animals injected with Strep-Qdot705 in complex with MCa Whole mouse imaging was performed immediately after Qdot injection. For organ imaging, mice were 
sacrificed $24 \mathrm{hrs}$ after Qdot injection, and various organs isolated for imaging. After imaging of the organs, the organs were preserved in $4 \%$ paraformaldehyde for tissue sectioning experiments. For blood collection, $200 \mu \mathrm{l}$ of 1000 UI heparin in PBS was injected into mice 2 hrs after injection with Qdots, then $100 \mu \mathrm{l}$ of blood were collected. All animal experiments are conducted in agreement with the "Principles of Laboratory Animal Care" (NIH publication n. 86-23, revised 1985). The guidelines of the French Ministry of Agriculture (87/848) and of the European Community (86/609/EEC) were also respected.

\subsection{Flow cytometry}

Live $\mathrm{CHO}$ cells were incubated with $\mathrm{MCa}_{\mathrm{b}}$ / Strep-Qdot complexes in PBS. Concentration and duration of this incubation is specified in the Results section. In some experiments, the effect of $5 \mathrm{mM}$ amiloride, a macropinocytosis inhibitor, was tested on cell penetration of Qdots. The cells were then washed twice with PBS to remove excess extracellular complexes. In addition, they were treated with $1 \mathrm{mg} / \mathrm{ml}$ trypsin (InVitrogen) for $10 \mathrm{~min}$ at $37^{\circ} \mathrm{C}$ to remove remaining extracellular membraneassociated complexes. After trypsin incubation, the cell suspension was centrifuged at $500 \mathrm{~g}$ and resuspended in PBS. Flow cytometry analyses were performed with live cells using a Becton Dickinson FACSCalibur flow cytometer (BD Biosciences). Data were obtained and analyzed using CellQuest software (BD Biosciences). Live cells were gated by forward/side scattering from a total of 10,000 events. In another set of experiments, similar flow cytometry analyses were performed with mouse blood cells. Briefly, $200 \mu \mathrm{l}$ of collected blood samples were added to $2 \mathrm{ml}$ PBS, centrifuged 5 min at $300 \mathrm{~g}$, the pellets resuspended and washed with PBS two more times. Finally, the pellets were resuspended in $200 \mu \mathrm{PBS}$ for flow cytometry analyses.

\subsection{Tissue sectioning}

Paraformaldehyde-treated isolated organs were embedded in OCT compound (VWR), and frozen with liquid nitrogen. 10- to $15-\mu \mathrm{m}$ thick cryosections (Leica cryomicrotome) were collected on microscope slides and fixed with $4 \%$ paraformaldehyde for $10 \mathrm{~min}$ at room temperature. Slides were used for staining and confocal analysis.

\subsection{Confocal microscopy}

For analysis of the subcellular localization of $\mathrm{MCa}_{\mathrm{b}}$ / Strep-Qdot complexes in CHO living cells, cells were incubated with the complexes in PBS for $2 \mathrm{hrs}$, and then washed with PBS. Immediately after 
washing, the plasma membrane was stained with $5 \mu \mathrm{g} / \mathrm{ml}$ FITC-conjugated concanavalin A (Molecular Probes) for $3 \mathrm{~min}$. Cells were washed once more with PBS and immediately analyzed by confocal laser scanning microscopy. In another set of experiments with living CHO cells, cells were incubated with $50 \mathrm{nM}$ lysotracker red DND-99 in PBS for $20 \mathrm{~min}$ at $37^{\circ} \mathrm{C}$ to determine whether the $\mathrm{MCa}_{\mathrm{b}} / \mathrm{Strep}$ Qdot655 complex co-localizes with endosomes after cell penetration. Cells were again washed with PBS and immediately visualized by confocal microscopy. For the analysis of DRG neurons, cells were fixed 20 min with $4 \%$ formaldehyde after penetration of the $\mathrm{MCa}_{\mathrm{b}} /$ Strep-Qdot655 complex, and the cytoskeleton stained with tuj1 (1:500, Covance) before confocal microscopy analyses. Finally, for the analysis of tissue sections, the sections were incubated with $50 \mathrm{nM}$ lysotracker red DND-99 in PBS for 20 min at $37^{\circ} \mathrm{C}$, washed with PBS, and analyzed by confocal microscopy. All analyses were performed using a Leica TCS-SP2 operating system. Alexa-488 (FITC) and tuj1 were excited at $488 \mathrm{~nm}$, Qdot655 and Qdot705 at $645 \mathrm{~nm}$, and Qdot585 and lysotracker red DND-99 at $545 \mathrm{~nm}$, and emission fluorescence were collected in z-confocal planes.

\subsection{Transmission electron microscopy}

CHO cells were incubated with $\mathrm{MCa}_{\mathrm{b}}$ / Strep-Qdot585 or $\mathrm{MCa}_{\mathrm{b}}$ / Strep-gold in PBS for $2 \mathrm{hrs,} \mathrm{and} \mathrm{then}$ washed with PBS. Plate-adherent cells were fixed with 2.5\% glutaraldehyde in $0.1 \mathrm{M}$ cacodylate buffer pH 7.4 during 2 hrs at room temperature. Cells were then washed with cacodylate buffer and post-fixed with $1 \%$ osmium tetroxyde in the same buffer for $1 \mathrm{hr}$ at $4^{\circ} \mathrm{C}$. After extensive washing with water, cells were then stained with $1 \%$ uranile acetate $\mathrm{pH} 4.0$ during $1 \mathrm{hr}$ at $4^{\circ} \mathrm{C}$. Cells were then serially dehydrated using progressively more graded alcohol (30\%-60\%-90\%-100\%-100\%-100\%) and infiltrated with a mix of $1 / 1$ epon/alcohol $100 \%$ during $1 \mathrm{hr}$ before several baths of fresh epon (Flukka) lasting 3 hrs. Finally, a capsule full of epon was deposited on the surface of the cells and the resin left to polymerise during $72 \mathrm{hrs}$ at $60^{\circ} \mathrm{C}$. The polymerised block was then detached from the culture plate and ultrathin sections of $70 \mathrm{~nm}$ of the cell monolayer were cut with an ultramicrotome (Leica). Sections were post-stained with $4 \%$ uranile acetate and lead citrate before being observed with an electron microscope at $80 \mathrm{kV}$ (JEOL 1200EX).

\subsection{Whole mouse and organ imaging system}

A home-made set-up, adapted from the commercially available Aequoria ${ }^{\mathrm{TM}}$ system from Hamamatsu, is used. The excitation device is composed of 144 LEDs emitting at $633 \mathrm{~nm}$ (adapted from the LuxiFlux $^{\mathrm{TM}}$ device available from Hamamatsu) and equipped with interference band pass filters 
(633BP10 nm from Schott) for a light illumination power of $2.4 \mu \mathrm{W} . \mathrm{mm}^{-2}$. The filtered fluorescence signal (filter RG665 from Schott) is measured by a cooled CCD Camera (Orca-AG, Hamamatsu), placed at $160 \mathrm{~mm}$ from the imaging field. For mouse imaging, the integration time used is $100 \mathrm{~ms}$, the gain of the camera is set at low and the binning is $1 \times 1$. For organ imaging, the integration time used is $200 \mathrm{~ms}$ (highly fluorescent organs: intestine, liver, kidneys) or $5 \mathrm{~s}$ (low fluorescent organs: brain, heart, testis, spleen, lungs, bladder). The Wasabi ${ }^{\mathrm{TM}}$ software (Hamamatsu) is used to drive the set-up and for image processing. Imaging was performed at each desired time point after Qdot injection into mouse as indicated in the Results section.

\section{Results}

\subsection{Evidence that MCa promotes Strep-Qdot cell entry}

Figure 1A shows the primary structure of $\mathrm{MCa}$, modified by an extra biotinylated lysine residue at its N-terminus. All concentrations provided in this study refer to Qdot concentration. The schematic representation of $\mathrm{MCa}_{\mathrm{b}}$ / Strep-Qdot is given in Figure 1B. The presence of several Strep molecules at the surface of Qdot (an average of 7 according to the provider), combined with the ability of one Strep molecule to bind up to four $\mathrm{MCa}_{\mathrm{b}}$ entities, provides the possibility to greatly vary the $\mathrm{MCa}_{\mathrm{b}} /$ Qdot ratio. For most experiments described herein, a 4/1/0.14 $\mathrm{MCa}_{\mathrm{b}} /$ Strep / Qdot ratio was used unless stated otherwise. A 2 hrs incubation of $100 \mathrm{nM}$ Strep-Qdot585 with CHO cells at 75\% confluence leads to no cell entry at all as inspected by confocal microscopy (Figure $1 \mathrm{C}$, top panel). In contrast, an important dot-shaped cytoplasmic labeling within CHO cells was observed when cells were incubated in the same conditions with $\mathrm{MCa}_{\mathrm{b}} / \mathrm{Strep}-\mathrm{Qdot} 585$ (Figure 1C, lower panel). $\mathrm{MCa}_{\mathrm{b}}$ also produces cell entry of Strep-Qdot655, a quantum dot of different emission wavelength, in living differentiated dorsal root ganglion neurons (2 hrs incubation, Figure 2A lower panel). Again, no cell entry of Strep-Qdot655 is observed in the absence of $\mathrm{MCa}_{\mathrm{b}}$ (Figure 2A upper panel). Since these primary cultures also contain glial cells, the neuronal specific tuj1 class III $\beta$-tubulin marker was used to discriminate between neurons and glial cells. Figure 2B indicates that both neurons and non neuronal cells have undergone cell penetration of $\mathrm{MCa}_{\mathrm{b}}$ / Strep-Qdot655.

\section{2. $M C a_{b} /$ Qdots cell entry relies on macropinocytosis and the complex ends up into endosomes}


$\mathrm{MCa}_{\mathrm{b}}$ / Strep-Qdot655 entry results in a punctuated cytoplasmic staining in CHO cells indicating that Qdots end up into endosomal structures. To challenge this hypothesis, $\mathrm{CHO}$ cells were labeled with lysotracker red DND-99, a marker of endosomal structures, and the staining compared to that of $\mathrm{MCa}_{\mathrm{b}} /$ Strep-Qdot655 (Figure 3A). As shown, there was an almost complete overlap between the two stainings in living cells indicating that one or several endocytic pathways should be responsible for cell entry of Strep-Qdots.

To confirm that $\mathrm{MCa}_{\mathrm{b}}$ / Strep-Qdots really end up into the endocytic pathway, a set of electron microscopic studies were performed. CHO cells were incubated for 2 hrs with $100 \mathrm{nM}$ of StrepQdot585 or $\mathrm{MCa}_{\mathrm{b}} /$ Strep-Qdot585, washed, fixed, sliced and observed under transmission electron microscopy as detailed in the supplementary section. In CHO cells, endosomes had normal appearances and Strep-Qdot585 presence was barely detectable (Figure 3B). The average surface of the endosomes were $0.111 \pm 0.091 \mu \mathrm{m}^{2}(\mathrm{n}=25)$. Strep-Qdot585 presence at the extracellular face of CHO cells was undetectable indicating a total lack of affinity of Strep-Qdot585 for the plasma membrane.

Normal endocytic structures devoid of Strep-Qdot585 were also observed (average surface of $0.122 \pm$ $\left.0.093 \mu \mathrm{m}^{2}, \mathrm{n}=25\right)$ in $\mathrm{CHO}$ cells incubated with $\mathrm{MCa}_{\mathrm{b}} /$ Strep-Qdot585. However, these cells also possessed larger vacuoles filled with Qdots (average surface of $0.386 \pm 0.151 \mu \mathrm{m}^{2}, \mathrm{n}=25$ ) that were not observed in control cells (Figure 3C). These structures lack coat proteins and their morphological features are typical of macropinosomes. Interestingly, $\mathrm{MCa}_{\mathrm{b}} /$ strep-Qdot585 presence was detected as well at the extracellular face of the plasma membrane of CHO cells (Figure 3D) owing to the affinity of $\mathrm{MCa}_{\mathrm{b}}$ for plasma membrane components [21]. This finding was expected since cells were not treated with trypsin after incubation with $\mathrm{MCa}_{\mathrm{b}} /$ Strep-Qdot585. $\mathrm{MCa}_{\mathrm{b}} /$ Strep-Qdot585 were not detected in the cytoplasm, either because they were absent at that location or because individual $\mathrm{MCa}_{\mathrm{b}} / \mathrm{Strep}$ Qdot585 is poorly electron dense. Since Qdots are more difficult to visualize by transmission electron microscopy than gold particles, we chose to use Strep-gold particles to confirm these findings. As shown, $\mathrm{MCa}_{\mathrm{b}}$ / Strep-gold particles were also found exclusively in endocytic structures and not in the cytoplasm (Figure 3E). Again, $\mathrm{MCa}_{\mathrm{b}}$ is responsible for the penetration of Strep-gold particles since $\mathrm{CHO}$ cells are devoid of particles in the absence of $\mathrm{MCa}_{\mathrm{b}}$ (Figure 3F). Finally, we also investigated whether the massive presence of $\mathrm{MCa}_{\mathrm{b}} /$ Strep-Qdot585 in endocytic structures is due to macropinocytosis. Figure $3 \mathrm{G}$ indicates that addition of $5 \mathrm{mM}$ amiloride during $\mathrm{MCa}_{\mathrm{b}} / \mathrm{Strep}$-Qdot585 incubation leads to an $84 \%$ reduction in the average $\mathrm{MCa}_{\mathrm{b}} /$ Strep-Qdot585 internalization, as assessed by flow cytometry (arbitrary mean fluorescence intensity of 104.3 and 16.4 for $\mathrm{MCa}_{\mathrm{b}}$ / Strep-Qdot585 treated $\mathrm{CHO}$ cells in the absence and presence of amiloride, respectively). We conclude that macropinocytosis is the major pathway of $\mathrm{MCa}_{\mathrm{b}} / \mathrm{Strep}-\mathrm{Qdot} 585$ entry into cells and that it leads to the 
formation of Qdot-enriched macropinosomes. The absence of macropinosomes in control cells (those not incubated with $\mathrm{MCa}_{\mathrm{b}}$ ) suggests that $\mathrm{MCa}_{\mathrm{b}} /$ Strep-Qdot585 binding at the surface of $\mathrm{CHO}$ cells triggers macropinocytosis. These findings are coherent with the observation that $\mathrm{MCa}_{\mathrm{b}} / \mathrm{Strep-Cy5}$ complexes also enter into $\mathrm{CHO}$ cell lines through macropinocytosis to end up into endosomes [21]. These results thus suggest that Qdot coupling to Strep do not alter the cell penetration mechanism of this cargo when coupled to $\mathrm{MCa}_{\mathrm{b}}$.

\subsection{Concentration-dependence and kinetics of $M C a_{b} /$ Strep-Qdot cell entry}

Previous studies have shown that $\mathrm{MCa}_{\mathrm{b}}$ / Strep-Cy5 cell entry occurs with a half-efficient penetration concentration $\left(\mathrm{PC}_{50}\right)$ of about $700 \mathrm{nM}$ [22] (with a 4/1 $\mathrm{MCa}_{\mathrm{b}} /$ Strep molar ratio). We thus checked how coupling Qdot585 with Strep could influence the $\mathrm{PC}_{50}$ value of $\mathrm{MCa}_{\mathrm{b}}$ for the penetration of Qdots (Figure 4A). CHO cells were incubated for two hours with variable concentrations of Strep-Qdot585 (with a fixed $\mathrm{MCa}_{\mathrm{b}} / \mathrm{Qdot} 585$ of $4 / 1$, equivalent to an estimated fixed $\mathrm{MCa}_{\mathrm{b}} /$ Strep ratio of $0.57 / 1$ ), washed, treated with trypsin to remove surface bound Qdots, and analyzed by flow cytometry. As shown, the measured $\mathrm{PC}_{50}$ value for Strep-Qdot585 cell penetration was $87 \pm 7 \mathrm{nM}$ in these conditions. Saturation was observed for $200 \mathrm{nM} \mathrm{MCa}_{\mathrm{b}} /$ Strep-Qdot585 meaning that reasonably low concentrations of Qdots can be used in cell penetration studies. Next, the importance of the $\mathrm{MCa}_{\mathfrak{b}} / \mathrm{Qdot585}$ ratio was investigated (Figure 4B). Increasing concentrations of $\mathrm{MCa}_{\mathrm{b}}$ were incubated (2 hrs) with a constant concentration of Strep-Qdot585 (50 nM) in order to increase the $\mathrm{MCa}_{\mathrm{b}} /$ StrepQdot ratio of the complexes. The FACS data indicate a 50\% Molar Ratio value $\left(\mathrm{MR}_{50}\right)$ of $20.4 \pm 17.8$. This value is close to the maximal theoretic value of 28 that can be reached when the average 7 Strep molecules of a single Strep-Qdot585 are saturated by the binding of $\mathrm{MCa}_{\mathrm{b}}$ molecules. For comparison the estimated $\mathrm{MCa}_{\mathrm{b}}$ / Strep ratios are also indicated in Figure 4B. Finally, the kinetics of Qdot cell entry was investigated by incubating $\mathrm{CHO}$ cells for increasing time durations with $50 \mathrm{nM} \mathrm{MCa} / \mathrm{Strep}$ Qdot585 (200 nM MCa $\mathrm{b}_{\mathrm{b}}$ complexed with $50 \mathrm{nM}$ Strep-Qdot585, MR value of 4). As shown, halfmaximal cell entry of $\mathrm{MCa}_{\mathrm{b}} /$ Strep-Qdot585 occurred at $60 \pm 3 \mathrm{~min}$. This is three-fold slower than the entry of $\mathrm{MCa}_{\mathrm{b}}$ / Strep-Cy5 as assessed from an earlier study [9].

\subsection{Effect of $M C a_{b}$ on the in vivo distribution of Strep-Qdot705}

Anesthetized OF1 mice were injected with Strep-Qdot705 or $\mathrm{MCa}_{\mathrm{b}} /$ Strep-Qdot705 and the resulting fluorescence measured on the whole animal as described in the supplementary section. Control animals (before injection) displayed very little auto-fluorescence (Figure 5A). Immediately after injection, a 
general fluorescence was observed throughout the body in both conditions. A very rapid rise in fluorescence levels of Strep-Qdot705 was observed within the liver after 15 min that lasted for 4 hours, indicating a preferential accumulation in this tissue. A similar time course of accumulation in the liver was observed for $\mathrm{MCa}_{\mathrm{b}}$ / Strep-Qdot705, although the intensity of fluorescence observed in the liver was weaker suggesting that $\mathrm{MCa}_{\mathrm{b}}$ kept Strep-Qdot705 longer in circulation. After 2 to 4 hours, the level of fluorescence within the liver decreases in both conditions, indicating body clearance and/or body redistribution of quantum dots into alternative organs. Whole animal imaging is however not discriminative enough to decide where and in what proportion the Qdots are distributed in the body. Therefore, the animals were sacrificed $24 \mathrm{hrs}$ after injection, the organs imaged and the fluorescence quantified. This time point was chosen to maximize the clearance of Strep-Qdot705 from the body and see the effect of $\mathrm{MCa}_{\mathrm{b}}$ on the cell penetration of Strep-Qdot705 in vivo. As compared to control organs from non-injected animals, Strep-Qdot705 and $\mathrm{MCa}_{\mathrm{b}} /$ Strep-Qdot705 distribute and accumulate into intestine, liver, kidneys, brain, testis, heart, spleen and lungs (Figure 5B). Quantification of the fluorescence accumulated into the organs reveal only mild differences in brain, spleen and liver (Figure 5C), suggesting that $\mathrm{MCa}_{\mathrm{b}}$ did not influence to major levels the distribution of Strep-Qdot705 in vivo.

\subsection{Coupling of $M C a_{b}$ to Strep-Qdot705 favors Qdot entry into cells in vivo}

$\mathrm{MCa}_{\mathrm{b}}$ is a cell penetrating peptide and has the capability to induce intracellular accumulation of Qdots in vitro. It was therefore of interest to determine whether this property of cell penetration of $\mathrm{MCa}_{\mathrm{b}}$ could be preserved in vivo. Because $\mathrm{MCa}_{\mathrm{b}}$ localizes Strep-Qdots into endosomes in vitro, we also used an endosomal marker to detect the intracellular presence of Strep-Qdots in vivo. Spleen from injected mice (Strep-Qdot705 or $\mathrm{MCa}_{\mathrm{b}} /$ Strep-Qdot705) were isolated after $24 \mathrm{hrs,} \mathrm{sectioned} \mathrm{and} \mathrm{stained} \mathrm{with}$ the endosomal marker lysotracker red DND-99. As shown in Figure 6A, clear co-localization between $\mathrm{MCa}_{\mathrm{b}} /$ Strep-Qdot705 and lysotracker red DND-99 was observed indicating that accumulation of Qdots in this organ results in cell penetration when $\mathrm{MCa}_{\mathrm{b}}$ is coupled to the Qdots. In contrast, no colocalization was observed when Strep-Qdots alone were injected in mice (Figure 6A). Also, fewer Qdots were observed in this later condition probably because of facilitated Qdot clearance in the absence of $\mathrm{MCa}_{\mathrm{b}}$. The first cells that $\mathrm{MCa}_{\mathrm{b}} /$ Strep-Qdot705 may encounter immediately after injection into the jugular vein are blood cells. Thus, we also examined whether blood cells could accumulate Strep-Qdots in the presence of $\mathrm{MCa}_{\mathrm{b}}$ (Figure 6B). As shown, by flow cytometry, the presence of $\mathrm{MCa}_{\mathrm{b}}$ leads to an increased fluorescence of blood cells from an average value of 19.9 to 31.5 (arbitrary units). In contrast, no differences were observed between the mean fluorescence levels of control blood cells 
or blood cells collected from mice injected with Strep-Qdot705 alone. These data indicate that, besides splenic cells, $\mathrm{MCa}_{\mathrm{b}}$ also favors cell penetration of Strep-Qdots into blood cells.

\section{Discussion}

In summary, these data indicate that $\mathrm{MCa}_{\mathrm{b}}$ is a good carrier for the cell penetration of Qdots in vitro and in vivo. It turns out to be an efficient vector since it is active at concentrations below the micromolar level. We confirm that, for Qdots also, the molar ratio between $\mathrm{MCa}_{\mathrm{b}}$ and Qdots has a positive influence on the level of the cell penetration of these Qdots. In the chemical configuration used here, using Strep as an attachment method, these Qdots concentrate massively into macropinosomes and are poorly or not released into the cytoplasm. From in vivo distribution studies, $\mathrm{MCa}$ does not dramatically affect the organ distribution of Qdots making it a neutral cell penetrating vector for targeting purposes. Further studies are envisioned to determine whether Qdots coupled or not to $\mathrm{MCa}_{\mathrm{b}}$ may cross the blood brain barrier. Qdots are interesting platforms for grafting biologically active molecules. It will also be of interest to determine whether in vivo intracellular delivery of $\mathrm{MCa}_{\mathrm{b}} /$ Strep-Qdots may be associated to biological activity. Further development will also be required to enhance the escape of endosomes for a delivery of Qdots into the cytoplasm.

\section{Acknowledgements}

We acknowledge financial support from a grant Emergence to MDW of the Région Rhône-Alpes, TIMOMA2, a research program of the Commissariat à l'Energie Atomique, and from the PNANO program of the Agence Nationale de la Recherche. NR is supported by a fellowship of the Emergence grant.

\section{References}

[1] Akerman M E, Chan W C, Laakkonen P, Bhatia S N and Ruoslahti E 2002 Nanocrystal targeting in vivo Proc Natl Acad Sci U S A 99 12617-21

[2] Ballou B, Lagerholm B C, Ernst L A, Bruchez M P and Waggoner A S 2004 Noninvasive imaging of quantum dots in mice Bioconjug Chem 15 79-86

[3] Boisseau S, Mabrouk K, Ram N, Garmy N, Collin V, Tadmouri A, Mikati M, Sabatier J M, Ronjat M, Fantini J and De Waard M 2006 Cell penetration properties of maurocalcine, a natural venom peptide active on the intracellular ryanodine receptor Biochim Biophys Acta 1758 308-19

[4] Chen F, Gerion, D. 2004 Fluorescent CdSe/ZnS nanocrystal-peptide conjugates for long-term, nontoxic imaging and nuclear targeting in living cells. Nano Lett 4 1827-32 
[5] Choi H S, Liu W, Misra P, Tanaka E, Zimmer J P, Itty Ipe B, Bawendi M G and Frangioni J V 2007 Renal clearance of quantum dots Nat Biotechnol 25 1165-70

[6] Dahan M, Levi S, Luccardini C, Rostaing P, Riveau B and Triller A 2003 Diffusion dynamics of glycine receptors revealed by single-quantum dot tracking Science 302 442-5

[7] Derfus A M, Chen, W.C.W., Bhatia, S.N. 2004 Intracellular delivery of quantum dots for live cell labeling and organelle tracking Adv Mater 16 961-6

[8] Dubertret B, Skourides P, Norris D J, Noireaux V, Brivanlou A H and Libchaber A 2002 In vivo imaging of quantum dots encapsulated in phospholipid micelles Science 298 1759-62

[9] Esteve E, Mabrouk K, Dupuis A, Smida-Rezgui S, Altafaj X, Grunwald D, Platel J C, Andreotti N, Marty I, Sabatier J M, Ronjat M and De Waard M 2005 Transduction of the scorpion toxin maurocalcine into cells. Evidence that the toxin crosses the plasma membrane J Biol Chem $\mathbf{2 8 0}$ 12833-9

[10] Gao X, Cui Y, Levenson R M, Chung L W and Nie S 2004 In vivo cancer targeting and imaging with semiconductor quantum dots Nat Biotechnol 22 969-76

[11] Hoshino A, Fujioka K, Oku T, Nakamura S, Suga M, Yamaguchi Y, Suzuki K, Yasuhara M and Yamamoto K 2004 Quantum dots targeted to the assigned organelle in living cells Microbiol Immunol 48 985-94

[12] Larson D R, Zipfel W R, Williams R M, Clark S W, Bruchez M P, Wise F W and Webb W W 2003 Water-soluble quantum dots for multiphoton fluorescence imaging in vivo Science $\mathbf{3 0 0}$ 1434-6

[13] Lee J, Kim J, Park E, Jo S and Song R 2008 PEG-ylated cationic CdSe/ZnS QDs as an efficient intracellular labeling agent Phys Chem Chem Phys 10 1739-42

[14] Lidke D S, Nagy P, Heintzmann R, Arndt-Jovin D J, Post J N, Grecco H E, Jares-Erijman E A and Jovin T M 2004 Quantum dot ligands provide new insights into erbB/HER receptormediated signal transduction Nat Biotechnol 22 198-203

[15] Lim Y T, Kim S, Nakayama A, Stott N E, Bawendi M G and Frangioni J V 2003 Selection of quantum dot wavelengths for biomedical assays and imaging Mol Imaging 2 50-64

[16] Mabrouk K, Ram N, Boisseau S, Strappazzon F, Rehaim A, Sadoul R, Darbon H, Ronjat M and De Waard M 2007 Critical amino acid residues of maurocalcine involved in pharmacology, lipid interaction and cell penetration Biochim Biophys Acta 1768 2528-40

[17] Mansson A, Sundberg M, Balaz M, Bunk R, Nicholls I A, Omling P, Tagerud S and Montelius L 2004 In vitro sliding of actin filaments labelled with single quantum dots Biochem Biophys Res Commun 314 529-34

[18] Michalet X, Pinaud F F, Bentolila L A, Tsay J M, Doose S, Li J J, Sundaresan G, Wu A M, Gambhir S S and Weiss S 2005 Quantum dots for live cells, in vivo imaging, and diagnostics Science 307 538-44

[19] Mosbah A, Kharrat R, Fajloun Z, Renisio J G, Blanc E, Sabatier J M, El Ayeb M and Darbon H 2000 A new fold in the scorpion toxin family, associated with an activity on a ryanodinesensitive calcium channel Proteins 40 436-42

[20] Pinaud F, King D, Moore H P and Weiss S 2004 Bioactivation and cell targeting of semiconductor CdSe/ZnS nanocrystals with phytochelatin-related peptides J Am Chem Soc 126 6115-23

[21] Ram N, Aroui S, Jaumain E, Bichraoui H, Mabrouk K, Ronjat M, Lortat-Jacob H and De Waard M 2008 Direct Peptide Interaction with Surface Glycosaminoglycans Contributes to the Cell Penetration of Maurocalcine J Biol Chem 283 24274-84

[22] Ram N, Weiss N, Texier-Nogues I, Aroui S, Andreotti N, Pirollet F, Ronjat M, Sabatier J M, Darbon H, Jacquemond V and De Waard M 2008 Design of a disulfide-less, pharmacologically-inert and chemically-competent analog of maurocalcine for the efficient transport of impermeant compounds into cells J Biol Chem 
[23] Santra S, Yang H, Stanley J T, Holloway P H, Moudgil B M, Walter G and Mericle R A 2005 Rapid and effective labeling of brain tissue using TAT-conjugated CdS:Mn/ZnS quantum dots Chem Commun (Camb) 3144-6

[24] Silver J and Ou W 2005 Photoactivation of quantum dot fluorescence following endocytosis Nano Lett 5 1445-9

[25] Sukhanova A, Devy J, Venteo L, Kaplan H, Artemyev M, Oleinikov V, Klinov D, Pluot M, Cohen J H and Nabiev I 2004 Biocompatible fluorescent nanocrystals for immunolabeling of membrane proteins and cells Anal Biochem 324 60-7

[26] Voura E B, Jaiswal J K, Mattoussi H and Simon S M 2004 Tracking metastatic tumor cell extravasation with quantum dot nanocrystals and fluorescence emission-scanning microscopy Nat Med 10 993-8

[27] Wadia J S and Dowdy S F 2002 Protein transduction technology Curr Opin Biotechnol 13 52-6 


\section{Figure legends}

Figure 1. $\mathrm{MCa}$ is a peptide vector for the cell entry of quantum dots. (A) Primary structure of biotinylated $\mathrm{MCa}$ with the $\mathrm{Cys}^{3}-\mathrm{Cys}^{17}$, $\mathrm{Cys}^{10}-\mathrm{Cys}^{21}$ and $\mathrm{Cys}^{16}-\mathrm{Cys}^{32}$ arrangement of its three disulfide bridges. The biotinylated lysine was positioned at the N-terminus of MCa. (B) Schematic diagram depicting the structural organization of $\mathrm{MCa}_{\mathrm{b}} / \mathrm{Strep}$-Qdot. The core can be composed of CdSe to form Qdot585 or Qdot655 or of CdTe to form Qdot705. Shell is composed of ZnS. The polymer coating is 2,000 Da molecular weight polyethyleneglycol $\left(\mathrm{PEG}_{2000}\right)$, to which an average of 7 Strep are immobilized. $\mathrm{MCa}_{\mathrm{b}} /$ Strep-Qdot are formed by the addition of a molar excess of $M C a_{b}$. (C) $\mathrm{MCa}_{\mathrm{b}}$ induces the cell penetration of Strep-Qdot585 into living CHO cells. In the absence of $\mathrm{MCa}_{\mathrm{b}}$, no cell penetration is observed (top panels). When CHO cells were incubated $2 \mathrm{hrs}$ with $100 \mathrm{nM}$ of $\mathrm{MCa}_{\mathrm{b}} /$ Strep-Qdot585, a punctuate cytoplasmic staining was observed (lower panels). Qdot fluorescence are indicated in left panels (red), plasma membrane staining with concanavalin A in middle panels (green), and merge pictures in right panels.

Figure 2. $\mathrm{MCa}_{\mathrm{b}}$ also allows cell entry of Qdot655 into neurons. (A) Cell entry of $100 \mathrm{nM}$ StrepQdot655 (upper panel) or $\mathrm{MCa}_{\mathrm{b}} /$ Strep-Qdot655 (lower panel) into live cells from primary cultures of dorsal root ganglions after $2 \mathrm{hrs}$ incubation. Qdot655 are in blue (left panels), and membrane staining with concanavalin A in green (middle panels). Right panels are merge pictures. (B) Same as in (A) except that cells were fixed with $4 \%$ paraformaldehyde and stained with tuj1 (green marker for neuronal class III $\beta$-tubulin).

Figure 3. $\mathrm{MCa}_{\mathrm{b}} /$ Strep-Qdot585 and $\mathrm{MCa}_{\mathrm{b}} /$ Strep-gold particles enter CHO cells by macropinocytosis and end up into endosomes. (A) Colocalization of $\mathrm{MCa}_{\mathrm{b}} / \mathrm{Strep}-\mathrm{Qdot} 585$ with the endosomal marker Lysotracker red DND-99 in living CHO cells. Transmission electron microscopy images of CHO cells incubated with Strep-Qdot585 alone (B), $\mathrm{MCa}_{\mathrm{b}} / \mathrm{Strep}-\mathrm{Qdot} 585$ (C, D), Strep-gold particles (E) or $\mathrm{MCa}_{\mathrm{b}}$ / Strep-gold particles (F). E: endosome; ER: endoplasmic reticulum; Mit: mitochondria; Mvb: multivesicular body; PM: plasma membrane. (G) Effect of $5 \mathrm{mM}$ amiloride on the cell penetration of $\mathrm{MCa}_{\mathrm{b}} /$ Strep-Qdot585. Cells were preincubated with $5 \mathrm{mM}$ amiloride for $45 \mathrm{~min}$, and then coincubated with the complex for an additional 2 hrs. Cell fluorescence was analyzed by flow cytometry. Control: cells that were incubated with Strep-Qdot585 in the absence of $\mathrm{MCa}_{\mathrm{b}}$. 
Figure 4. Dose- and time-dependent cell penetration of $\mathrm{MCa}_{\mathrm{b}} /$ Strep-Qdots. (A) Mean fluorescence level produced by $\mathrm{MCa}_{\mathrm{b}}$ / Strep-Qdot585 penetration into CHO cells as a function of Strep-Qdot585 concentration. Mean fluorescence levels assessed by flow cytometry. Molar ratio of $\mathrm{MCa}_{\mathrm{b}}$ versus Qdot585 is 4/1 and time of incubation with $\mathrm{CHO}$ cells $2 \mathrm{hrs}$. Data were fitted with a sigmoid function $\mathrm{MF}=\mathrm{MF}_{\max } /\left(1+\exp \left(-\left(\mathrm{X}-\mathrm{PC}_{50}\right) / \mathrm{b}\right)\right)$ where $\mathrm{MF}$ is the mean fluorescence, $\mathrm{MF}_{\max }=854 \pm 45, \mathrm{PC}_{50}=87 \pm$ $7 \mathrm{nM}$, and $\mathrm{b}$ the slope $=29 \pm 5 \mathrm{nM}$. a.u. = arbitrary units. (B) Mean fluorescence level produced by $\mathrm{MCa}_{\mathrm{b}} /$ Strep-Qdot585 penetration into CHO cells as a function of the molar ratio between $\mathrm{MCa}_{\mathrm{b}}$ and Qdot585 (lower scale), or $\mathrm{MCa}_{\mathrm{b}}$ and Strep (top scale). Qdot585 concentration was $50 \mathrm{nM}$ and $\mathrm{CHO}$ cells were incubated $2 \mathrm{hrs}$ with the complexes. Fit of the data as in (A) yield $\mathrm{MF}_{\max }=479 \pm 171, \mathrm{MR}_{50}=$ $20 \pm 17 \mathrm{nM}$, and $\mathrm{b}$ the slope $=23 \pm 9 \mathrm{nM}$. (C) Time course of cell penetration of $\mathrm{MCa}_{\mathrm{b}} /$ StrepQdot585. Qdot concentration is $50 \mathrm{nM}$ and $\mathrm{MCa}_{\mathrm{b}} /$ Qdot ratio is 4/1. Data were fitted as in (A) and (B) and yield $\mathrm{MF}_{\max }=222 \pm 11$, half-maximal penetration at $60 \pm 2 \mathrm{~min}$, and $\mathrm{b}$ the slope $=15 \pm 3 \mathrm{~min}$.

Figure 5. In vivo distribution of Strep-Qdot705 and effect of $\mathrm{MCa}_{\mathrm{b}}$. (A) Time course of the in vivo distribution of Strep-Qdot705 (top panels) and $\mathrm{MCa}_{\mathrm{b}}$ / Strep-Qdot705 (lower panels) by whole animal imaging. Left middle panel shows the auto-fluorescence of a mouse before injection and the fluorescence intensity scale. (B) Fluorescence levels of organs from control mouse (top panels), 24 hrs after injection of Strep-Qdot705 (middle panels), or $24 \mathrm{hrs}$ after injection of $\mathrm{MCa}_{\mathrm{b}} /$ Strep-Qdot705 (lower panels). (C) Quantification of fluorescence intensity of isolated organs from control, StrepQdot705 and $\mathrm{MCa}_{\mathrm{b}} /$ Strep-Qdot705 mice.

Figure 6. Intracellular delivery of Strep-Qdots in vivo by $\mathrm{MCa}_{\mathrm{b}}$. (A) Confocal microscopy images of spleen tissue sections showing the distribution of Strep-Qdot705 (top panels) and $\mathrm{MCa}_{\mathrm{b}} / \mathrm{Strep}$ Qdot705 (lower panels). (B) Flow cytometry analyses of blood cells collected $2 \mathrm{hrs}$ after injection of Strep-Qdot705 or $\mathrm{MCa}_{\mathrm{b}} /$ Strep-Qdot705 into mice. 